\title{
Exploring Change in the Relative Abundance of Marine Megafauna in the Bay of Biscay, 2004-2016
}

\author{
Authier Matthieu ${ }^{1,{ }^{*}}$, Doremus Ghislain ${ }^{1}$, Van Canneyt Olivier ${ }^{1}$, Boubert Jean-Jacques ${ }^{1}$, \\ Gautier Gérard ${ }^{1}$, Doray Mathieu ${ }^{2}$, Duhamel Erwan ${ }^{3}$, Masse Jacques ${ }^{2}$, Petitgas Pierre ${ }^{2}$, \\ Ridoux Vincent ${ }^{1,4}$, Spitz Jérome ${ }^{1}$
}

${ }^{1}$ Observatoire PELAGIS UMS 3462 CNRS-ULR, Université de La Rochelle, 5 allée de l'Océan, 17000 La Rochelle, France

${ }^{2}$ Ifremer Centre Atlantique, Unité Écologie et Modèles pour l'Halieutique (EMH), Rue de l'Ile d'Yeu, BP 21105, 44311 Nantes Cedex 03, France

${ }^{3}$ Ifremer Station de Lorient, Laboratoire de Technologie et de Biologie Halieutique (LTBH), 8 rue

François Toullec, 56100 Lorient, France

${ }^{4}$ Centre d'Études Biologiques de Chizé (CEBC), UMR 7372 CNRS-ULR, 79360 Villiers en Bois, France

* Corresponding author : Matthieu Authier, email address : authierm@gmail.com

\begin{abstract}
:
Conservation has moved from species-centered to ecosystem-based approaches: the Marine Strategy Framework Directive requires the maintenance or restoration of 'Good Environmental Status' of all European marine waters. Monitoring biodiversity at the scale of whole ecosystems is salient, but challenging owing to the large spatial scale involved and the large spatio-temporal heterogeneity of marine ecosystems. We capitalized on the integrated ecosystemic PELGAS survey carried out in spring in the Bay of Biscay to document patterns of change in marine megafauna relative abundance at the community level over more than a decade (2004-2016). The relative abundance of the twenty three most frequently sighted species (6 cetaceans and 17 seabirds) was estimated by distance sampling, and averaged over the study period and area. Temporal changes were investigated with a Dynamic Factor Analysis. This exploratory analysis suggested that approximately one third of all species showed an increase, another third a decrease, and the last third no overall change in relative abundance. The relative abundance of offshore species, including that of all studied cetaceans, slightly increased in spring between 2004 and 2016. Further investigations will correlate the uncovered changes at the marine megafauna community level with concommittent biological and oceanographic processes that are routinely monitored on the PELGAS integrated ecosystemic surveys.
\end{abstract}




\section{Highlights}

- Monitoring biodiversity is essential to marine conservation in Europe. Marine megafauna (cetaceans and seabirds) are important nodes in foodwebs. Trajectories of megafauna relative abundance in the Bay of Biscay were contrasted. Offshore species tended to increase in relative abundance over the study period. One third of the studied species tended to decrease between 2004-2016.

Keywords : marine megafauna, relative abundance, MSFD, ecosystemic surveys 
1 - Introduction

Human activities are altering the majority of ecosystems on Earth, resulting in a fast erosion of biodiversity (Ceballos et al. 2015). Because threats to biodiversity need to be tackled at the scale of whole ecosystems, conservation has moved from species-centered and pressure-by-pressure approaches to holistic approaches (Noss 1990, Armsworth et al. 2007). For instance, the European Union issued in 2008 the ambitious Marine Strategy Framework Directive (MSFD, 2008/56/EC) to maintain or restore the 'Good Environmental Status': “the environmental status of marine waters where these provide ecologically diverse and dynamic oceans and seas which are clean, healthy and productive" (EC 2008).

The MSFD embodies an iterative, learning and knowledge-based approach (Bigagli 2015) whose backbone is the Activities-Pressure-State-Response framework (Shepard et al. 2015). The MSFD requires knowledge on human activity-pressure links and pressure-state causal relationships to design an integrated monitoring programme articulated around eleven descriptors of marine ecosystems. Whereas Noss (1990) bemoaned how it was a minor consideration in environmental policy, biodiversity is currently the first and most central descriptor of 'Good Environmental Status' within MSFD (Cochrane et al. 2016). Some components of the MSFD biodiversity descriptor deal with marine megafauna (marine mammals, seabirds, marine turtles and large fishes). These species are often top predators (Sergio et al. 2014) that have a disproportionate effect, with respect to their abundance or biomass, on the structure of marine food webs (Baum \& Worm 2009; but on an ecosystemic evaluation of top predators in the Bay of Biscay, see Lassalle et al. 2012).

Monitoring top predators is salient to biodiversity conservation policy, but challenging owing to the large spatial scale involved (Runge et al. 2014) and the large spatio-temporal heterogeneity of marine ecosystems (Fisher et al. 2015). The heterogeneity of marine waters translates into large variations in biodiversity measurements: quantifying change in the face of a low signal-to-noise ratio is a challenging endeavour (Yoccoz et al. 2001, Buckland et al. 2011). Abundance, that is the number of individuals of a species living in an area at a given time, is an essential biodiversity variable whose systematic monitoring can inform on critical ecosystem-level changes (Schmeller et al. 2017). Although the MSFD biodiversity descriptor for marine megafauna requires abundance estimation and monitoring at the level of ecosystems (EC 2017), absolute at-sea abundance estimates can be extremely difficult to obtain for highly mobile species such as cetaceans $(e . g$. Hammond et al. 2013) and seabirds. 
Because they require dedicated surveys over large areas, absolute estimates are usually produced infrequently and come with substantial uncertainty that depresses statistical power to detect change (Taylor et al. 2007, Jewell et al. 2012, ICES 2014). For example, absolute abundance estimates for cetacean species are collected roughly every ten years for the Small Cetaceans Abundance in the North Sea and Adjacent Areas (SCANS surveys; Hammond et al. 2013) or every six years for the SAMM surveys (Laran et al. 2017). In contrast, estimates of relative abundance, which can also suffer from a low precision, can leverage more statistical power to detect change because data can be collected more frequently and in tandem with other surveys.

In this study, we capitalized on the integrated ecosystemic PELGAS («Pélagiques Gascogne») survey carried out every year since 2003 during spring in the Bay of Biscay to study marine mammals and seabirds. We focused on unveiling patterns of change in their relative abundance at the community level over more than a decade (2004-2016). Our outlook was mainly descriptive and exploratory (Glass \& Hall 2008, Gerring 2012, Leek \& Peng 2015). PELGAS data are valuable in this respect as they span more than a decade and can provide baseline information prior to the MSFD initial assessment of 2012. This feature is particuliarly salient given how the lack of baselines may result in defining 'Good Environmental Status' pragmatically as the current status, even when the latter already corresponds to a degraded ecosystem. Within the broader MSFD context of monitoring at the scale of the marine ecosystems, documenting yearly variations can complement absolute abundance estimates derived from dedicated, but infrequent, surveys in order to assess progress, or regress, towards 'Good Environmental Status'.

\section{2 - Materials \& Methods}

\section{1 - Study Area}

The North-East Atlantic Ocean is one of the 4 marine regions considered in the MSFD, and is further divided into ecologically coherent sub-regions, among which is the "Bay of Biscay and the Iberian Coast". The Bay of Biscay per se is an open oceanic bay whose central, oceanic area is characterised by a weak clockwise circulation. Winds and tides mainly drive currents over the shelf, which is large in the Northern part and narrow in the Southern part of the bay (Figure 1). Freshwater discharges from large rivers result in a low-salinity gradient from coastal to oceanic waters (Mason et al. 2006). In April-May, sea surface temperatures begin to warm and a seasonal thermocline develops over the shelf (Mason et al. 2006). Spring oceanographic features in the Bay of Biscay that affect marine megafaune can be very dynamic and fast changing (Huret et al. this issue). The study area encompassed mainly shelf waters of the Bay of Biscay in the French and 
adjacent Spanish Economic Exclusive Zones. It is part of the larger MSFD sub-region "Bay of Biscay and the Iberian Coast", and is located between $43.5-48.5^{\circ} \mathrm{N}$ (ICES statistical areas VIIIa, b, $\mathrm{c}, \mathrm{d}$; Figure 1). The Bay of Biscay is a dynamic and biologically rich pelagic ecosystem where both boreal and subtropical species occur.

\section{2 - Data Collection}

After in pilot study conducted in 2003, sighting data on marine megafauna (marine mammals, marine turtles, seabirds, and large fish) were collected onboard R/V "Thalassa" during the PELGAS spring campaign between 2004 and 2016. Briefly, transects orthogonal to the main isobaths are covering the shelf area of the Bay of Biscay from the coasts to the shelf break. PELGAS primary aim is the assessment of small pelagic fish stocks (Figure 1); see Doray et al. this issue for a detailed overview of PELGAS. A team of three trained Marine Mammal and Seabird Observers (MMSO) carried out data collection following a distance sampling protocol (Buckland et al. 2015). Survey effort (vessel speed > 8 knots), observation conditions (glare, cloud, cover, sea state, etc) and the precise GPS location of each sighting are recorded from dawn till dusk. Along a transect, a leg corresponded to a portion of effort surveyed in the same observation conditions: whenever the latter changed (e.g. a change in ship activity, sea state or MMSO team) a new leg started. Two MMSOs were each operating on one side of the upper bridge (16 $\mathrm{m}$ above sea level) or inside the bridge (14 $\mathrm{m}$ above sea level) when outdoor conditions deteriorated. MMSOs searched for marine megafauna with naked eyes within an angle of $90^{\circ}$ from the side to the bow. Binoculars were only used for species identification upon detection. Identification was carried out to the lowest possible taxonomic level. Photos were systematically taken to validate species identification for cetaceans and for seabirds when in doubt. For each sighting, MMSOs assessed animal behaviour (e.g. attracted to the ship). Assessing behaviour can be difficult, especially attraction to the ship, and can include a substantial subjective component. Attraction was assumed whenever was detected an animal with a travelling course that pointed straight to the bow or to the stern of the ship. Every hour one MMSO was relieved from duty by the third MMSO to reduce observer fatigue. Any change in MMSO team composition triggered a leg change: a leg was thus at most one-hour long and observation bouts for any MMSO lasted at most two hours followed by a one-hour break. For each sighting, a MMSO estimated the (radial) distance with a graduated stick calibrated to measure distances from the horizon when held at their eye-level. Each stick was MMSO specific, and had two scales: one for observing from the upper bridge and the other for observing inside the bridge. The angle of each sighting was estimated with an angleboard. Estimated distances and angles of flying seabirds is prone to a greater measurement error than those of seabirds sitting on the water or cetaceans. To minimise this source of error in subsequent analyses, perpendicular 
distances were binned, and a half-normal detection function was always fitted (see section 2.3). All MMSOs were trained at the Observatoire PELAGIS to adhere to the protocol, and to identify marine megafauna occuring in the Bay of Biscay.

\section{3 - Distance Sampling Analyses}

Data were curated validated and archived into the MEGASCOPE database managed by Observatoire PELAGIS (Dorémus 2016). Legs were split in segments of 2,000 m with statistical software R v. 3.3.2 (R Core Team 2016) and the package 'adehabitatLT' (Calenge 2006). Observation conditions and sightings were matched to each segment. Animals following or attracted to the ship were systematically excluded from further analyses. Animals may, however, be attracted long before they are detected by MMSO. Attraction can induce an upward bias in density estimates, but we assumed this bias to be constant and focused on interpreting relative variations only. Sightings associated with human activities in the Bay of Biscay were excluded (e.g. seabirds following a fishing vessel close to the transect line). Distance analyses were carried out with the statistical software R v. 3.3.2 (R Core Team 2016) and the 'distsamp' function in library 'unmarked' (Fiske \& Chandler 2011). This function implements the model of Royle et al. (2004) and allows us to incorporate two types of covariates, some affecting the detection process and others affecting the abundance process: measurement error and process variance are thus explicitly modelled and distinguished (King 2014). The following covariates were extracted at the mid-point of each segment to model abundance effects: bathymetric depth and slope, distance to shelf break (all computed from GEBCO-08 30 arc second database; Becker et al. 2009) and latitude. These covariates were used to model the abundance of all studied species, except the European Shag (Phalacrocorax aristotelis) where the effect of bathymetric depth was set to 0 because of numerical instability in the estimated coefficient. Beaufort sea state and platform height (bridge or upper bridge) were included respectively as a continuous and categorical covariate affecting detection. A half-normal detection function was used for all species analysed.

Twenty-three species sighted at least 15 times between 2004 and 2016 were included in the analysis (Table 1). For each, a model with all the aforementioned covariates was fitted. The aim was to have a common model across species, not to find the best fitting model specification for each species. This common model can be seen as a measurement instrument for exploratory analyses: we did not try to find the best fitting model for each studied species, that is we traded realism for generality (Levins 1966) in order to facilitate a community-level assessment of the marine megafauna in the Bay of Biscay. If numerical problems occurred during model fitting (e.g. an implausibly large estimated coefficient with an extremely large standard error), the model was pruned from the problematic covariates until convergence was reached. The most common case corresponded to 
species that were never detected when observers were on the bridge, and it was not possible to include plateform height as a covariate in the detection process. For species with few detections, the effect of Beaufort sea state on detection could not be estimated. Estimated coefficients affecting abundance and detection were extracted for further exploratory analysis with multivariate statistics (see section 2.4). Model specification and estimated coefficients for the 23 studied species are summarized in online Supplementary Table 1.

After model fitting, relative abundance for each segment was predicted (using the 'ranef' function of R package 'unmarked') and used as data in a block averaging procedure (Petitgas et al. 2014) to generate maps (see online Supplementary Materials). Briefly, this procedure averages data by $0.25^{\circ}$ $\mathrm{x} 0.25^{\circ}$ block over a spatial grid spanning the study area, with the origin of the blocks being drawn at random in the lower left corner of the grid. The block-averaged data is similar to a kernel interpolation (Petitgas et al. 2014). The mean density in the area surveyed every year during the integrated PELGAS survey (Figure 1) was extracted from yearly maps to produce time series of relative density (see section 2.5). Approximate $80 \%$ confidence bounds were computed assuming a lognormal distribution for densities.

\section{4 - Principal Component Analysis}

Two Principal Component Analyses (PCA) were carried out with R v. 3.3.2 (R Core Team 2016) on the regression coefficients estimated from the distance sampling analyses: one on the coefficients associated with abundance effects, and the other on those linked to detection. The aim was to summarize the multivariate coefficients from distance sampling models to a couple of dimensions to reveal the location of marine megafauna species in static environmental space. Bathymetric depth and slope, distance to shelf break and latitude are all covariates without substantial variations between years, yet they can often predict the distribution of marine megafauna at large spatial scales. Distribution patterns at the level of the marine megafauna community was investigated with PCA: since covariates were considered for relative abundance prediction in distance sampling models (section 2.3), a PCA on estimated coefficients provided a summary of the environmental space. PCA did not allow investigating temporal variations since coefficients were assumed timeinvariant.

\section{5 - Dynamic Factor Analysis}

To reveal the trajectory of marine megafauna abundances between 2004 and 2016, we used a Dynamic Factor Analysis (DFA; Zuur et al. 2003, Holmes et al. 2012). DFA aims at modelling a large panel of $n$ time series of length $T$ as a linear combination of a smaller number $m$ of latent 
variables called 'factors'. These factors are common to all time series and are modelled as a random walk. They provide a concise description of the cross-sectional correlation pattern between the original time series. DFA is a data reduction technique adapted to short and non-stationary time series that seek to reveal the hidden commonalities between the latter. The DFA model with a single factor is:

$$
\left\{\begin{array}{c}
\mathbf{z}_{t} \sim \operatorname{MVN}\left(\boldsymbol{\Lambda} \boldsymbol{\alpha}_{t}, \boldsymbol{R}\right), \mathbf{z}_{t}=\left(z_{\text {species } \left._{1}, \ldots, z_{\text {species }_{n}}\right)_{t}^{\prime}}\right. \\
\alpha_{t} \sim N\left(\alpha_{t-1}, \sigma\right), t \in[2: T] \\
\alpha_{1} \sim N(0, \sigma)
\end{array}\right.
$$

where $z_{t}$ is a $n$-vector of response data at time $t, \boldsymbol{\alpha}=\left(\alpha_{1}, \ldots, \alpha_{T}\right)^{\prime}$ is a $T$-vector corresponding to the common factor, $\boldsymbol{\Lambda}=\left(\Lambda_{\text {species }_{1}}, \ldots, \Lambda_{\text {species }_{n}}\right)^{\prime}$ is a $n$-vector of species-specific loading; and $\boldsymbol{R}$ is a residual $n$ by $n$ covariance matrix. Time series of the (geometric) average density for the 23 studied species were fitted with DFA using package 'MARSS' (Holmes et al. 2013) in statistical software R v. 3.3.2. Each time series was $\log$-transformed $\left(y^{*}=\log \left(y / \sqrt{1+\mathrm{cv}_{y}^{2}}\right)\right)$, then $\mathrm{z}$-scored (i.e demeaned and standardized to have unit variance; Zuur et al. 2003). The rationale to keep all species in the same DFA analysis was the following: were there any differences between broad taxonomic groups (seabirds and cetaceans), these would be evidenced by different latent factors. In order words, we expected a priori $m>1$. Models with up to three common factors $(m \in[1: 3])$ were tested. Two parsimonious structural assumptions with respect to the residual covariance matrix were tested: $\boldsymbol{R}$ was either assumed diagonal with equal variance and zero covariance, or nondiagonal with equal variance and equal covariance. Model selection was done using the Akaike Information Criterion corrected for small sample size (AICc).

The analytical workflow used in this study is depicted in Figure 2.

3 - Results

Survey effort ranged from a minimum of $3,519 \mathrm{~km}$ in 2004 to a maximum of $6,742 \mathrm{~km}$ in 2010 (annual mean \pm standard deviation: 4,960 $\pm 915 \mathrm{~km}$ ). 34,342 segments were used in the distance sampling analyses. For each segment, the recorded number of the 23 most frequently sighted species of marine megafauna, including 6 cetacean and 17 bird species, was tallied (Table 1). Cetaceans and seabirds most often detected were the Common Dophin (Delphinus delphis) and the Northern Gannet (Morus bassanus) respectively (Figure 3A). The effective strip half-width in 
average observation conditions was estimated from a half-normal detection function for every studied species (Figure 3B). Effective strip half-width were overall less than 400 metres for bird species, and less than 250 metres for smaller-sized species; and between 450 and 800 metres for cetaceans (Table 1). Average densities (over the area surveyed every year between 2004 and 2016) are depicted on Figure 4: densities were the highest (>0.1 ind per $\mathrm{km}^{2}$ ) for Northern Gannets and Lesser Black-Backed Gulls (Larus fuscus). They were the lowest $\left(<0.001\right.$ ind per $\mathrm{km}^{2}$ ) for European Shags, Minke Whales (Balaenoptera acutorostrata), Parasitic Skuas (Stercorarius parasiticus), Razorbills (Alca torda), Great Black-Backed Gulls (Larus maritimus), and Risso's Dolphins (Grampus griseus). Maps and detection functions are available in online Supplementary Figures S1-S23.

Results from the PCA on estimated coefficients of the distance sampling models are summarized on Figure 5. Increased Beaufort sea-state and observations from the vessel bridge had a negative effect on the detection of cetacean species (Figure 5A). Results with respect to bird species were less clear-cut: some species were more easily detected with increased Beaufort (Manx Shearwater Puffinus puffinus, Balearic Shearwater Puffinus mauretanicus, Common Tern Sterna hirundo, and Black Legged Kittiwake Rissa tridactyla). The detection of Northern Fulmars (Fulmar glacialis), Great Skuas (Catharacta skua) and Sandwich Terns (Sterna sandvicensis) was unaffected by Beaufort. The remaining seabird species were less frequently detected with increased Beaufort. Cetacean abundance increased in the Southern part of the Bay of Biscay (Figure 5B) and was associated with greater bathymetric depths (Striped Dolphin Stenella coeruleoalba, Bottlenose Dolphin Tursiops truncatus, Long-finned Pilot Whale Globicephala melas, Risso's Dolphin) and steeper bathymetric slopes (Common Dolphin, Minke Whale). Some seabird species were more abundant in the Northern part of the Bay of Biscay (European Shag, Great Black-Backed Gull, Razorbill, Manx Shearwater) or in shallower waters (Herring Gull Larus argentatus, Common Murre Uria aalge, Balearic Shearwater, Sandwich Tern).

The DFA model with the smallest AICs included a single latent factor (Table 2, Figure 6). This factor corresponded to a slightly increasing trend during the study period: the pattern was a decrease before 2008 and after 2011 with an increase between these two periods (Figure 6). Studied species fell into three distinct groups with respect to their patterns of change in relative abundance from 2004 to 2016. All cetacean species, as well as Razorbills, loaded positively on the common factor. Species which loaded negatively on the latent factor included Herring and Lesser Black-backed Gulls, the Parasitic Skua, the two Tern species, the European Storm Petrel (Hydrobates pelagicus) and the Northern Fulmar. The estimated loading for the most sighted species, the Northern Gannet, 
was close to zero, resulting in no trend over the study period. No trend was also evidenced for Balearic and Manx Shearwaters; Great Black-backed Gulls and Black-legged Kittiwakes; Great Cormorants (Phalacrocorax carbo) and European Shags; Common Murres and Great Skuas.

\section{4 - Discussion}

We documented the relative abundance of the marine megafauna community in the Bay of Biscay over more than a decade. Our analysis relied first on using a common distance sampling model across the community of most sighted marine megafauna species in the Bay of Biscay; then on using exploratory statistical techniques such as PCA and DFA on the outputs of the first step (Figure 2).

To estimate relative abundance we used distance sampling modelling, which tackles the problem of detectability. Imperfect detection is an important source of variations in measurements (Yoccoz et al. 2001, Royle et al. 2004, Buckland et al. 2011, Monk 2014) but was not addressed in previous investigations conducted in the Bay of Biscay (Kiszka et al. 2007, Hémery et al. 2007, Certain et al. 2008). Distance sampling represents the state of the art methodology to estimate cetacean abundance (e.g. Hammond et al. 2013), but its use with respect to seabirds (Barbraud \& Thiebot 2009, Ronconi \& Burger 2009) is more controversial. Concerns boil down to whether biased results may stem from unmet assumptions when attempting to correct for imperfect detection. Distance sampling analyses assume that all animals are detected on the transect line, radial distance and angle are measured without error; and animals are detected at their initial location (Buckland et al. 2015, Glennie et al. 2015). However, these assumptions are unlikely to hold in practice. Perfect detection on the transect line is unlikely for diving animals. Radial distance and angle from the ship are difficult to ascertain for flying seabirds, introducing more measurement error compared to cetaceans and seabirds sitting on water. To mitigate this problem, the model of Royle et al. (2004) was preferred because it requires to bin distances into discrete classes (here between 5 and 10 depending on the number of detection for a given species, Table 1) instead of using the measured distances.

The relative speed of animals to that of the ship and animal movement can also introduce bias (Barbraud \& Thiebot 2009, Glennie et al. 2015): bias may be more pronounced with seabird species as they can move faster than cetaceans. Consequently, only effort with ship speed above 8 knots (approx. $15 \mathrm{~km}$ per hour) was retained, and animals attracted to or following the ship were systematically excluded. There are however no easy fix to these biases once a line transect survey is completed (Glennie et al. 2015). No correction for known biases (e.g. availability bias, attraction) 
was attempted in this study. Foregoing such corrections mean bias in estimates, but it also means an increased precision (Schmidt et al. 2017), which is also important to detect change. Because our focus was on variations in relative abundance only, we traded bias for precision and assumed any bias in data sampling and analyses would be constant over the study period. To substantiate this assumption, the same model specification was used across all studied species. Nevertheless, with respect to sampling, the effective strip half-width estimated for seabirds $(<400 \mathrm{~m})$ are plausible and comparable to previous empirical studies on similarly sized species (e.g. Barbraud \& Thiebot 2009). In order to avoid overconfident claims, and because our primary aim was to document the community pattern of relative variations in marine megafauna abundance, we used a common distance sampling model for all studied species, followed by multivariate statistics suited for exploratory analyses (Figure 2).

To describe the marine megafauna in the Bay of Biscay, PCAs were performed on the regression coefficients estimated from fitted distance sampling models (Figures $2 \& 5$ ). These coefficients summarized the effects of observation conditions (Beaufort sea state and platform height) and static physiographic features of the environment on the detection and abundance of marine megafauna in the Bay of Biscay. With respect to marine megafauna abundance, the two first PCA axes can be interpreted as reflecting a latitudinal and offshore gradient respectively (Figure 5B). Overall, cetacean species were more abundant in the Southern part of the Bay of Biscay, and some bird species, such as Black-legged Kittiwakes, Great Black-backed Gulls, Razorbills, Northern Fulmars or Manx Shearwaters were more abundant in the Northern part. The latter result reflect how the core breeding range of these latter species is further north to the Bay of Biscay (Heaney et al. 2002, Hémery et al. 2007). Although PCA provided a description of the main environmental features affecting marine megafauna in the Bay of Biscay, it could not describe temporal changes. The description provided was limited however to the static environmental covariates included in distance sampling analyses (Figure 2). Incorporating dynamic features (e.g. primary production, sea level anomalies) could provide further insight but was beyond the scope of this study.

To investigate temporal changes, we used another ordination technique: a DFA at the community level of marine megafauna in the Bay of Biscay. Because our purpose was descriptive, no environmental covariates were included in DFA, but abundance time series were first obtained from distance sampling analyses that relied on environmental covariates (Figure 2). DFA was performed on species with different feeding ecology, including contact dipping, plunge-diving, shallow-diving or deep-diving species. Surprisingly, a single factor model had the greatest support (Table 2, Figure 6). Factor loadings for cetaceans, as well as that of Razorbills, were all positive. For Razobills, our 
results are coherent with those of Le Rest et al. (2016) who evidenced from aerial surveys an increased in abundance of auks between the winters of 2001-2002 and 2011-2012 after the Erika oil spill in the Bay of Biscay in December 1999. Species with negative factor loadings included Arctic, Sandwich and Common Terns, and Herring and Lesser Black-Backed Gulls: their relative abundance had decreased over the study period. This overall negative trajectory in relative abundance in the Bay of Biscay is consistent with trends of seabirds breeding in the United Kingdom (JNCC 2016), north to the Bay of Biscay. Relative abundance of European Storm Petrels in the Bay of Biscay decreased over the study period, which is consistent with the at-sea survey results of Hémery et al. (2007). Finally, one third of the studied species, including the most commonly detected species, the Northern Gannet, was not well described by the common factor (Figure 6). More complex DFA could accommmodate more time-series at the expense of parsimony (Table 2). Short time series may partly explain why a one factor model was best supported by the data. Time-series in this study nevertheless spanned more than a decade, which corresponds to the minimum period recommended by the International Union for the Conservation of Nature to assess change in abundance (IUCN 2010).

Capitalizing on the PELGAS spring surveys, which exemplifies the strength of an integrated ecosystemic campaign (Shephard et al. 2015), we documented variations in relative abundance of marine megafauna over more than a decade. PELGAS surveys allowed consistency in both data acquisition and quality; which in turn allowed studying the community-level patterns of change in the Bay of Biscay. Of the 23 species included, one third exhibited an increase, another third a decrease; and the last third no overall change in relative abundance between 2004 and 2016. The taxonomic and functional breadth covered by the studied species make it unlikely that all species were subjected to the same pressures. We thus documented a community-level pattern that may not hold for every individual species. That our focus was here pattern-orientated should not distract from the fact that data collected on PELGAS span all trophic levels (Doray et al. this issue). Process-based analyses to elucidate drivers of changes can be undertaken, but required first a common data format (Petitgas et al. this issue).

Because integrated surveys such as PELGAS collect data across the different nodes (e.g. basal: phytoplankton; intermediate: small pelagic fish; and apical: marine top predators) of marine food webs, they allow correlating patterns with processes and impacts. Inferences on processes are needed to meet the requirement of the ecosystem approach embodied in MSFD. The MSFD is not limited to monitoring change in marine ecosystems, but also aims to address, and eventually remove, the pressures whose impact on ecosystems prevent to reach or maintain "Good 
Environmental Status". Implementing effective measures requires, however, a monitoring programme calibrated to document and detect changes over time. This study was a stepping stone towards fulfilling the ambitious goals of the MSFD with respect to monitoring marine megafauna in the Bay of Biscay. In particular, the trajectory in relative abundance estimated by DFA at the community level (Figure 6) can complement absolute abundance estimates. For example, absolute abundance estimates for cetacean species in the Bay of Biscay are collected every 10 (Hammond et al. 2013) or 6 years (Laran et al. 2017). Because the integrated PELGAS survey is annual, it can inform both on relative abundance variations between two distant dedicated surveys, and on progress towards "Good Environmental Status".

\section{5 - Acknowledgements}

We are indebted to the many highly motivated and dedicated MMSOs who have taken part into the integrated PELGAS surveys: Aurore Aubail, Marco Ballardini, Stéphane Baty, Alain Beaufils, Vincent Bretille, Florence Caurant, Grégoire Certain, Willy Dabin, Cécile Dars, Olivier Dian, Stéphane Dixneuf, Jean-Paul Delabruyère, Hélène Falchetto, Thibaut Gauquelin, Sébastien Gautier, Laurence Gonzalez, Virginie Lahaye, Charlotte Lambert, Véronique Magnin, Paula MendezFernandez, Hélène Peltier, Claire Pusineri, David Robert, Begoña Santos, Jeremy Tornos, Samuel Uzan-Allard. We thank two anonymous reviewers and the Associate Editor for helpful comments which led to a much improved version of this manuscript. 
References

Armsworth P. R., Chan K. M. A., Daily G. C., Ehrlich P. R., Kremen C., Ricketts T. H., Sanjayan M. A., 2007. Ecosystem-Service Science and the Way Forward for Conservation. Conservation Biology, 21, 1383-1384

Barbraud, C., Thiebot, J-B., 2009. On the Importance of Estimating Detection Probabilities from atSea Surveys of Flying Seabirds. Journal of Avian Biology, 40, 584-590.

Baum J. K., Worm B., 2009. Cascading Top-Down Effects of Changing Oceanic Predator Abundances. Journal of Animal Ecology, 78, 699-714

Becker J. J., Sandwell D. T., Smith W. H. F., Braud J., Binder B., Depner J., Fabre D., Factor J., Ingalls S., Kim S-H., Ladner R., Marks K., Nelson S., Pharaoh A., Trimmer R., Von Rosenberg J., Wallace G., Weatherall P., 2009. Global Bathymetry and Elevation Data at 30 Arc Seconds Resolution: SRTM30_PLUS. Marine Geodesy, 32(4), 355-371, http://www.gebco.net/

Bigagli, E., 2015. The EU Legal Framework for the Management of Marine Complex SocioEcological Systems. Marine Policy, 54, 44-51.

Buckland S.T., Studeny A.C., Magurran A., Newson S. E., 2011. Chapter 3: Biodiversity Monitoring: the Relevance of Detectability in Biological Diversity: Frontiers in Measurement and Assessment (A. Magurran \& B. J. McGill Editors), 1st Edition, Oxford University Press, pages 2536.

Buckland S.T., Rexstad, E.A., Marques, T.A., Oedekoven, C.S., 2015. Distance Sampling: Methods and Applications. Springer, Methods in Statistical Ecology, 1st Edition. Doi:10,1007/978-3-31919219-2

Calenge C., 2006. The Package 'adehabitat' for the R Software: Tool for the Analysis of Space and Habitat use by Animals. Ecological Modelling, 197, 516-519

Ceballos G., Ehrlich P. R., Barnosky A. D., Garcia A., Pringle R. M., Palmer T. M., 2015. Accelerated Modern Human-Induced Species Losses: Entering the Sixth Mass Extinction. Science Advances, 1, 1-5 
Certain G., Ridoux V., Van Canneyt O., Bretagnolle, V., 2008. Delphinid Spatial Distribution and Abundance Estimates over the Shelf of the Bay of Biscay. ICES Journal of Marine Science, 65, 656-666

Cochrane S. K. J., Andersen J. H., Berg T., Blanchet H., Borja A., Carstensen J., Elliott M., Hummel H., Niquil N., Renaud P. E., 2016. What Is Marine Biodiversity? Towards Common Concepts and Their Implications for Assessing Biodiversity Status. Frontiers in Marine Science, 3, 248, 10.3389/fmars.2016.00248

Doray M., Petitgas P., Romagnan J-B., Huret M., Duhamel E., Dupuy C., Spitz J., Authier M., Sanchez F., Berger L., Dorémus G., Bourriau P., Grellier P., Massé J., this issue. The PELGAS Survey: Ship-Based Integrated Monitoring of the Bay of Biscay Pelagic Ecosystem. Progress in Oceanography.

Dorémus G., 2016. Observatoire PELAGIS boat surveys 2003-2015. OBIS-SEAMAP (http://seamap.env.duke.edu/dataset/1403).

European Commission, 2008. Directive 2008/56/EC of the European Parliament and of the Council of 17 June 2008 establishing a framework for community action in the field of environmental policy (Marine Strategy Framework Directive). OJ L 164, 25.06.2008

European Commission, 2017. Commission Decision (EU) 2017/848 of 17 May 2017 laying down criteria and methodological standards on good environmental status of marine waters and specifications and standardised methods for monitoring and assessment, and repealing Decision 2010/477/EU (Text with EEA relevance). OJ L 125, 18.05.2017

Fisher J. A. D., Casini M., Frank K. T., Möllmann C., Leggett W. C., Daskalov G., 2015. The Importance of Within-System Spatial Variation in Drivers of Marine Ecosystem Regime Shifts. Philosphical Transactions of The Royal Society B, 370(1659), 1-8. doi:10.1098/rstb.2013.0271

Fiske I., Chandler R., 2011. unmarked: An R Package for Fitting Hierarchical Models of Wildlife Occurrence and Abundance. Journal of Statistical Software, 43(10), 1-23. URL http://www.jstatsoft.org/v43/i10/. 
Gerring J., 2012. Mere Description. British Journal of Political Science, 42, 721-746

Glass D. J., Hall N., 2008. A Brief History of the Hypothesis. Cell, 134, 378-381

Glennie R., Buckland S., Thomas L., 2015. The Effect of Animal Movement on Line Transect Estimates of Abundance. PLoS ONE, 10, e0121333

Hammond P., Macleod K., Berggren P., Borchers D., Burt L., Cañadas A., Desportes G., Donovan G., Gilles A., Gillespie D., Gordon J., Hiby L., Kuklik I., Leaper R., Lehnert K., Leopold M., Lovell P., Øien N., Paxton C., Ridoux V., Rogan E., Samarra F., Scheidat M., Sequeira M., Siebert U., Skov H., Swift R., Tasker M., Teilmann J., Van Canneyt O., Vázquez J., 2013. Cetacean Abundance and Distribution in European Atlantic Shelf Waters to Inform Conservation and Management. Biological Conservation, 164, 107-122

Heaney V., Ratcliffe N., Brown A., Robinson P. J., Lock L., 2002. The Status and Distribution of European Storm-Petrels Hydrobates Pelagicus and Manx Shearwaters Puffinus puffinus on the Isles of Scilly. Atlantic Seabirds, 4(1), 1-16.

Hémery G., D'Amico F., Castège I., Dupont B., D'Elbée J., Lalanne Y., Mouches C., 2008. Detecting the impact of oceano-climatic changes on marine ecosystems using a multivariate index: the case of the Bay of Biscay (North Atlantic-European Ocean). Global Change Biology, 14, 27-38. doi: 10.1111/j.1365-2486.2007.01471.x

Holmes E. E., Ward E. J., Wills K., 2012. MARSS: Multivariate Autoregressive State-space Models for Analyzing Time-series Data. The R Journal. 4(1), 11-19

Holmes E. E., Ward E. J., Wills K., 2013. MARSS: Multivariate Autoregressive State-Space Modeling. R package version 3.9.

Huret et al. (this issue). Progress in Oceanography.

ICES, 2014. ICES Advice May 2014: OSPAR Request on Implementation of MSFD for Marine Mammals. Information document 13.3.1 presented at the the 21st ASCOBANS Advisory Committe Meeting, Gothenburg, Sweden, 29 September - 1 October 2014. 19 pages. 
IUCN Standards and Petitions Subcommittee, 2010. Guidelines for Using the IUCN Red List Categories and Criteria. Version 8.1.

Jewell R., Thomas L., Harris C., Kaschner K., Wiff R., Hammond P., Quick N., 2012. Global Analysis of Cetacean Line-Transect Surveys: Detecting Trends in Cetacean Density. Marine Ecology Progess Series, 453, 227-240

JNCC, 2016. Seabird Population Trends and Causes of Changes: 1996-2015 Report (http://jncc.defra.giv.uk/page-3201). Joint Nature Conservation Committe, Updated September 2016. Pages 2886, 2887, 2890, 2895 and 2896 accessed on 2017/02/02.

Kaschner K., Quick N. J., Jewell R.,Williams R., Harris C. M., 2012. Global Coverage of Cetacean Line-Transect Surveys: Status Quo, Data Gaps and Future Challenges. PLoS One, 7, e44075

King R., 2014. Statistical Ecology Annual Review of Statistics and Its Applications, 1, 401-426

Laran S., Authier M., Blanck A., Dorémus G., Falchetto H., Monestiez P., Pettex E., Stefan É., Van Canneyt O., Ridoux V., 2017. Seasonal Distribution and Abundance of Cetaceans within French Waters - Part II: the Bay of Biscay and the English Channel. Deep Sea Research Part II, 141, 31-40

Lassalle G., Gascuel D., Le Loc'h F., Lobry J., Pierce G., Ridoux V., Santos M. B. Spitz J., Niquil N., 2012. An Ecosystem Approach for the Assessment of Fisheries Impacts on Marine Top Predators: the Bay of Biscay Case Study. ICES Journal of Marine Science, 69, 925-938

Leek J., Peng R., 2015. What is The Question? Science, 347, 1314-1315

Le Rest K., Certain, G., Debétencourt, B., Bretagnolle, V., 2016. Spatio-Temporal Modelling of Auk Abundance after the Erika Oil Spill and Implications for Conservation. Journal of Applied Ecology, 53, 1862-1870

Levins R., 1966. The Strategy of Model Building in Population Biology. American Scientist, 54, 421-431 
Mason E., Coombs S., Oliveira P., Angélico M. M., Stratoudakis, Y., 2006. An overview of the literature concerning the oceanography of the eastern North Atlantic region. Relat. Cient.Téc. Inst. Invest. Pescas Mar., Série Cooperação, 51 pp.

McGill B., Dornelas M., Gotelli N., Magurran A., 2015. Fifteen Forms of Biodiversity Trend in the Anthropocene. Trends in Ecology \& Evolution, 30, 104-113

Monk J., 2014. How Long Should We Ignore Imperfect Detection of Species in the Marine Environment when Modelling their Distribution? Fish and Fisheries, 15, 352-358

Petitgas P., Doray M., Huret M., Massé J. \& Woillez M., 2014. Modelling the Variability in Fish Spatial Distributions over Time with Empirical Orthogonal Functions: Anchovy in the Bay of Biscay. ICES Journal of Marine Science, 71(9), 2379-2389

Petitgas P., Huret M., Dupuis C., Spitz J., Authier M., Romagnan J-B., Doray M., this issue. Ecosystem Spatial Structure Revealed by Integrated Survey Data. Progress in Oceanography.

R Core Team, 2016. R: A language and environment for statistical computing. R Foundation for Statistical Computing Vienna Austria. URL https://www.R-project.org/.

Ronconi R. A., Burger A. E., 2009. Estimating Seabird Densities from Vessel Transects: Distance Sampling and Implications for Strip Transects. Aquatic Biology, 4, 297-309.

Royle J. A. Dawson D. K., Bates S., 2004. Modeling abundance effects in distance sampling. Ecology 85, 1591-1597.

Runge C. A., Martin T. G., Possingham H. P., Willis S. G., Fuller R. A., 2014. Conserving Mobile Species. Frontiers in Ecology and the Environment, 12, 395-402

Schmeller D. S., Weatherdon L. V., Loyau A., Bondeau A., Brotons L., Brummitt N., Geijzendorffer I. R., Haase P., Kuemmerlen M., Martin C. S., Mihoub J-B., Rocchini D., Saarenmaa H., Stoll S., Regan E. C., 2017. A Suite of Essential Biodiversity Variables for Detecting Critical Biodiversity Change. Biological Reviews doi:10.1111/brv.12332 
Schmidt J. H., Wilson T. L., Thompson W. L., Reynolds J. H., 2017. Improving Inference for Aerial Surveys of Bears: the Importance of Assumptions and the Cost of Unnecessary Complexity Ecology and Evolution, 1-10

Sergio F., Schmitz O. J., Krebs C. J., Holt R. D., Heithaus M. R., Wirsing A. J., Ripple W. J., Ritchie E., Ainley D., Oro D., Jhala Y., Hiraldo F. \& Korpimaki E., 2014. Towards a Cohesive, Holistic View of Top Predation: a Definition, Synthesis and Perspective. Oikos, 123, 1234-1243

Shephard S., van Hal R., de Boois, I., Birchenough S. N. R., Foden J., O'Connor J., Geelhoed S. C. V., Van Hoey G., Marco-Rius F., Reid D. G., Schaber M., 2015. Making Progress towards Integration of Existing Sampling Activities to Establish Joint Monitoring Programmes in support of MSFD. Marine Policy, 59, 105-111

Taylor B., Martinez M., Gerrodette T., Barlow J., Hrovat Y., 2007. Lessons from Monitoring Trends in Abundance of Marine Mammals. Marine Mammal Science, 23, 157-175

Yoccoz N., Nichols J., Boulinier T., 2001. Monitoring of Biological Diversity in Space and Time. Trends in Ecology \& Evolution, 16, 446-453

Zuur A., Fryer R., Jolliffe I., Dekker R., Beukema J., 2003. Estimating Common Trends in Multivariate Time Series using Dynamic Factor Analysis. Environmetrics, 14, 665-685 


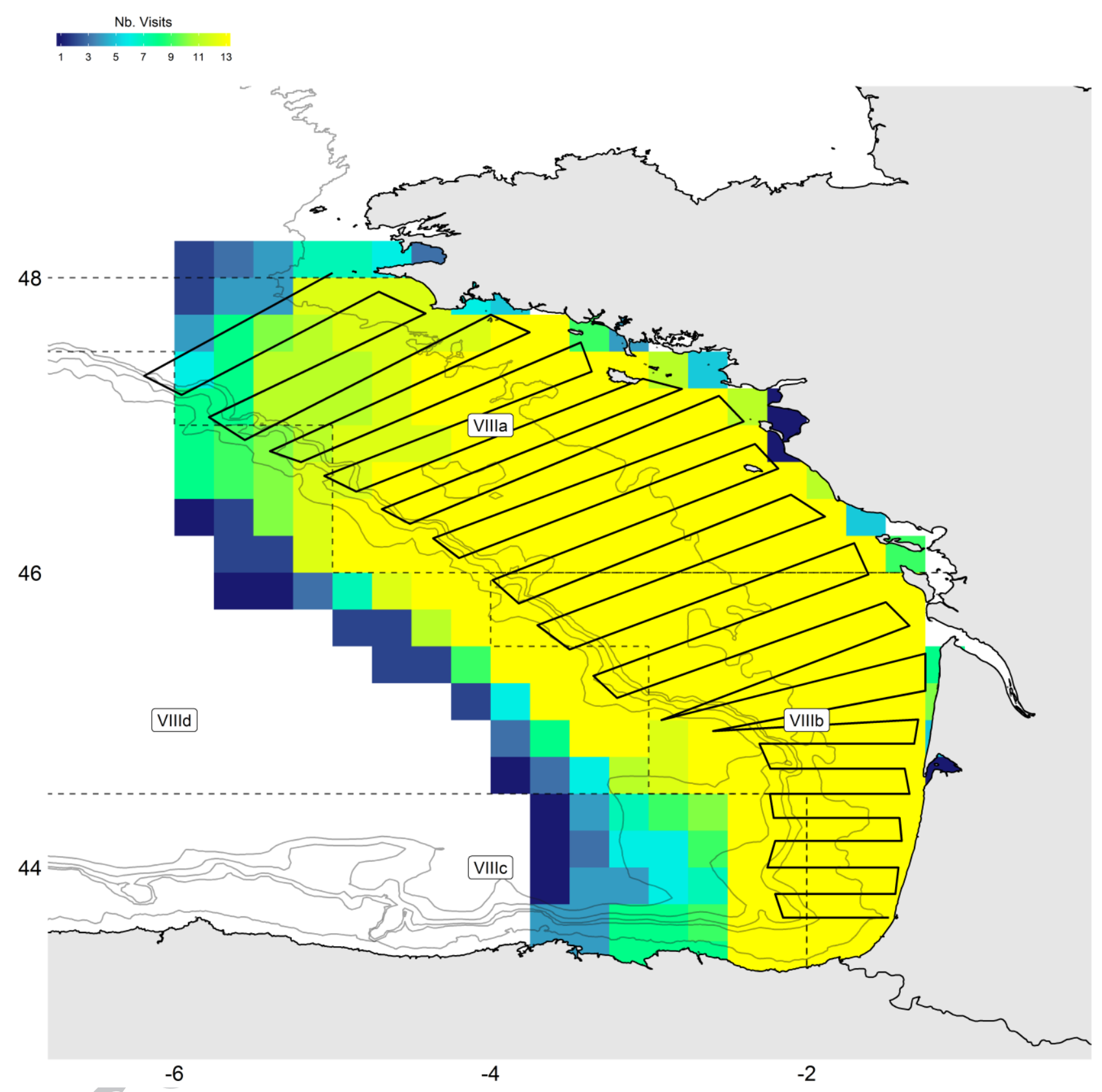

Figure 1: Map of the studied area in the Bay of Biscay. Color shading codes how many year a given $0.25^{\circ} \times 0.25^{\circ}$ block was visited between $2004-2016$. Isobaths are depicting in light gray. ICES statistical areas in the Bay of Biscay are lineated by dashed grey lines. Black lines represent the survey transects. 


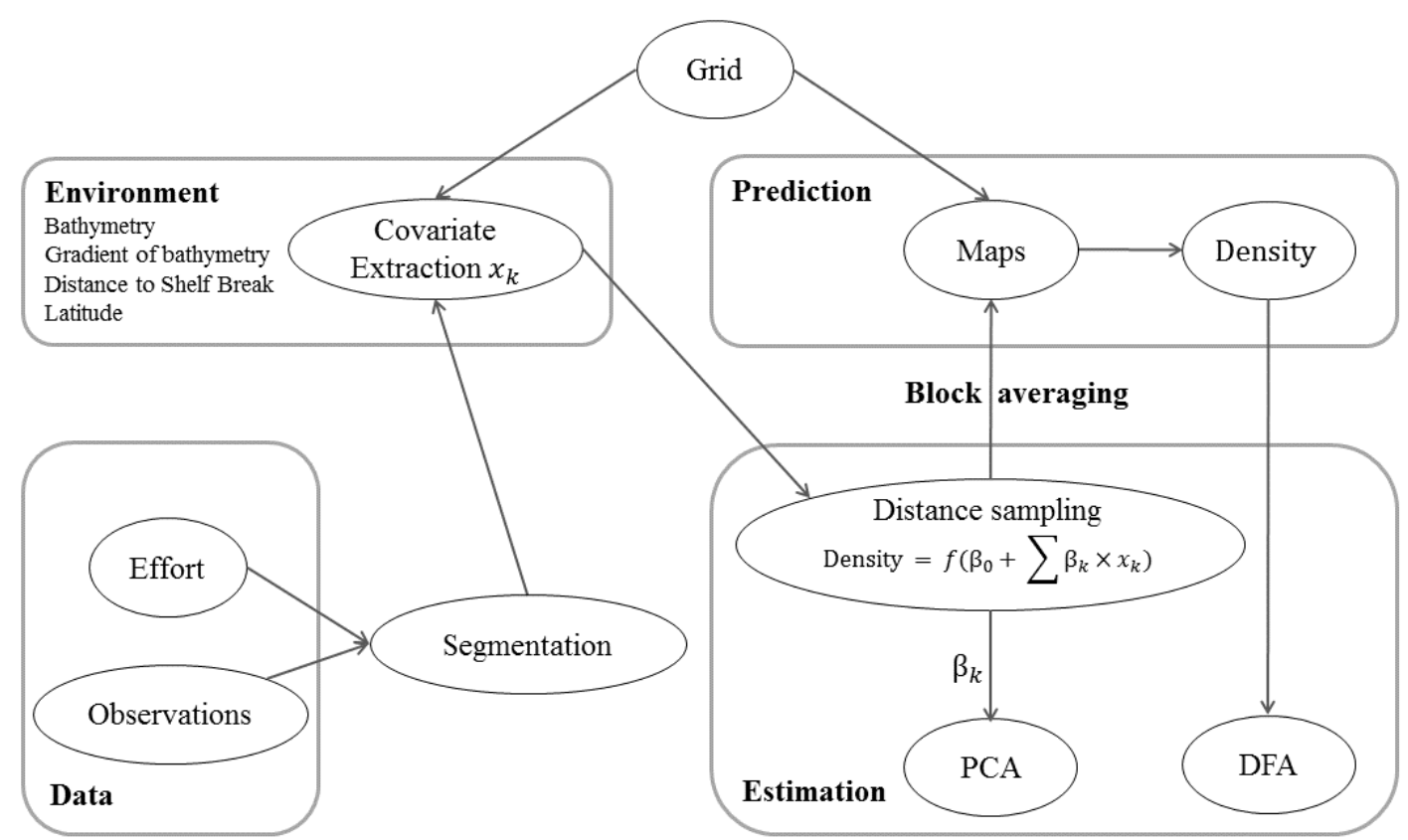

Figure 2: Flowchart diagram illustrating the different analytical steps taken in this study (see section 2).PCA: Principal Component Analysis; DFA: Dynamic Factor Analysis. 
A

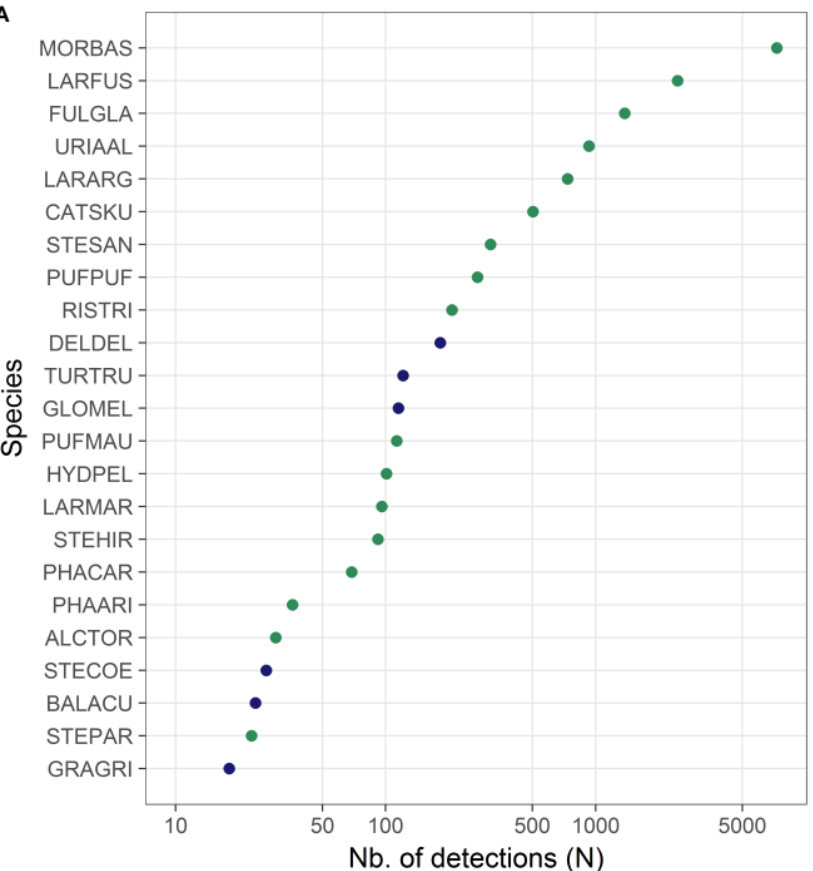

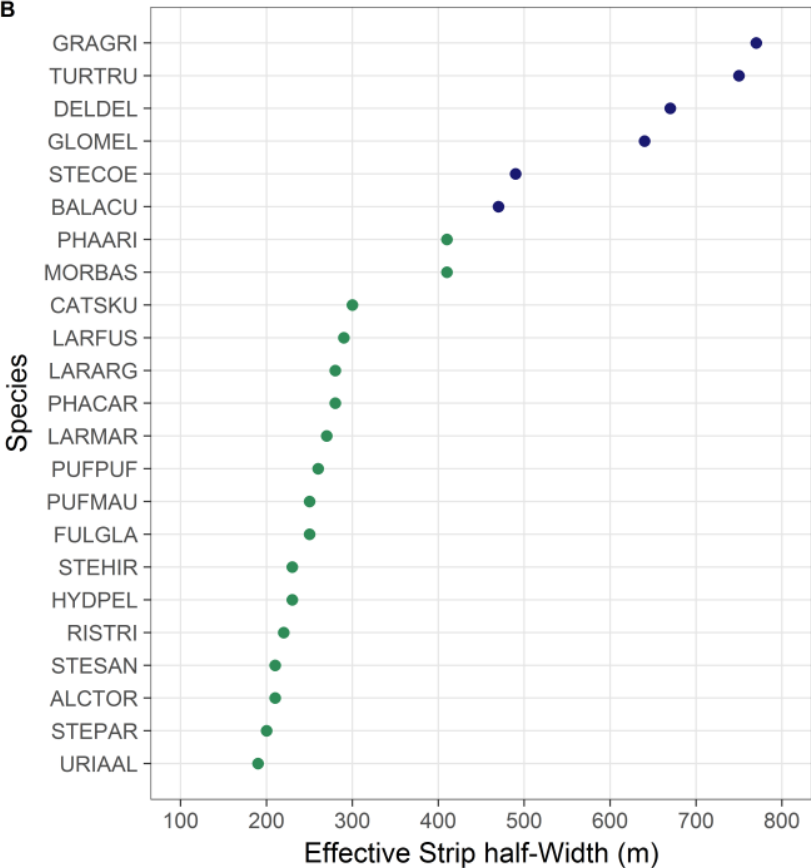

Figure 3: Total number marine megafauna sightings between 2004 and 2016 in the Bay of Biscay (left, panel A; x-axis on a logarithmic scale); and effective strip half-width estimated from a halfnormal detection function (right, panel B). Marine mammals are in blue and seabirds in green. 


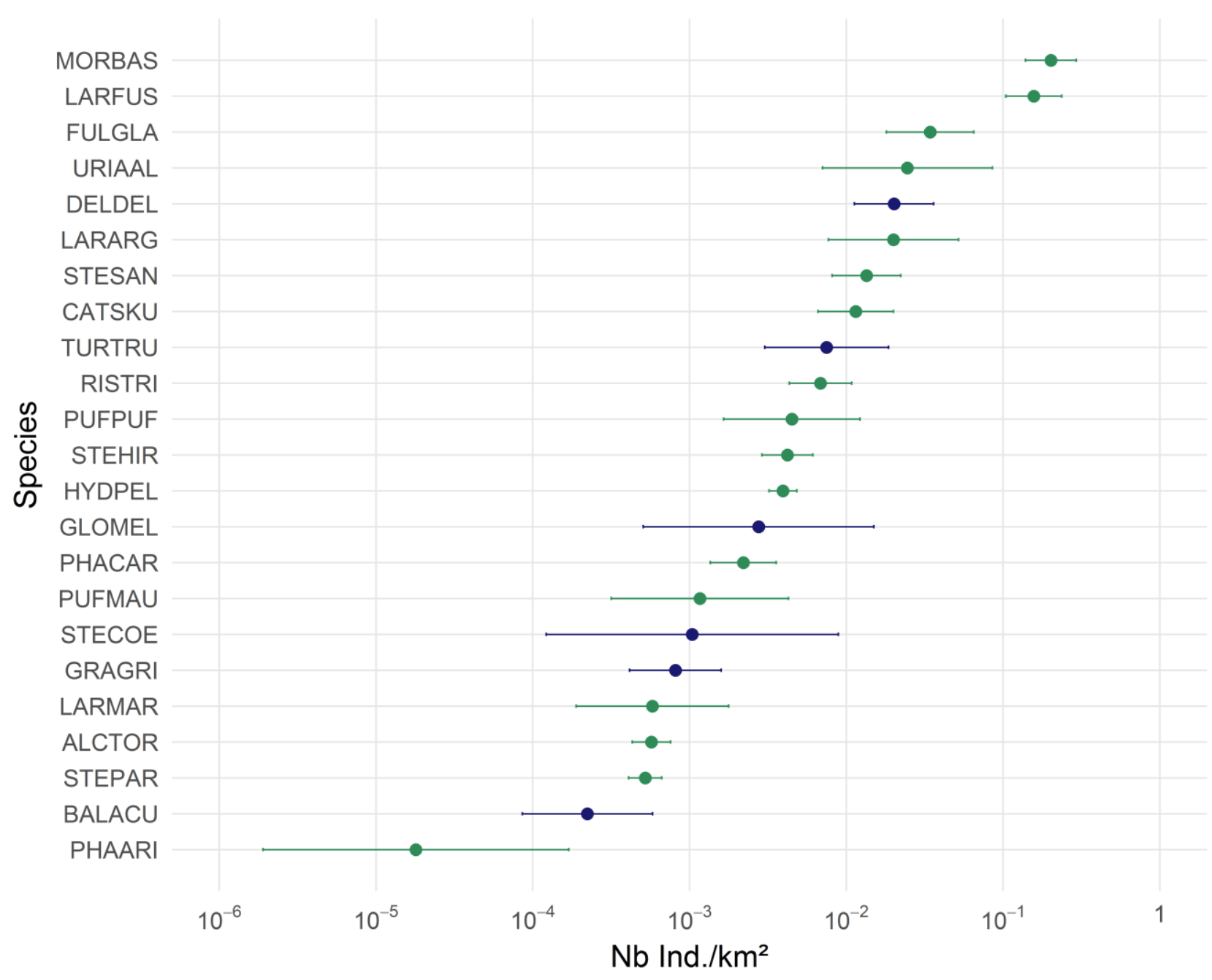

Figure 4: Average relative densities of marine megafauna species in the Bay of Biscay. Densities were first averaged over the area surveyed every year between 2004 and 2016. The geometric mean is reported (x-axis on a logarithmic scale), along with an approximate $80 \%$ confidence interval. Marine mammals are in blue and seabirds in green. 

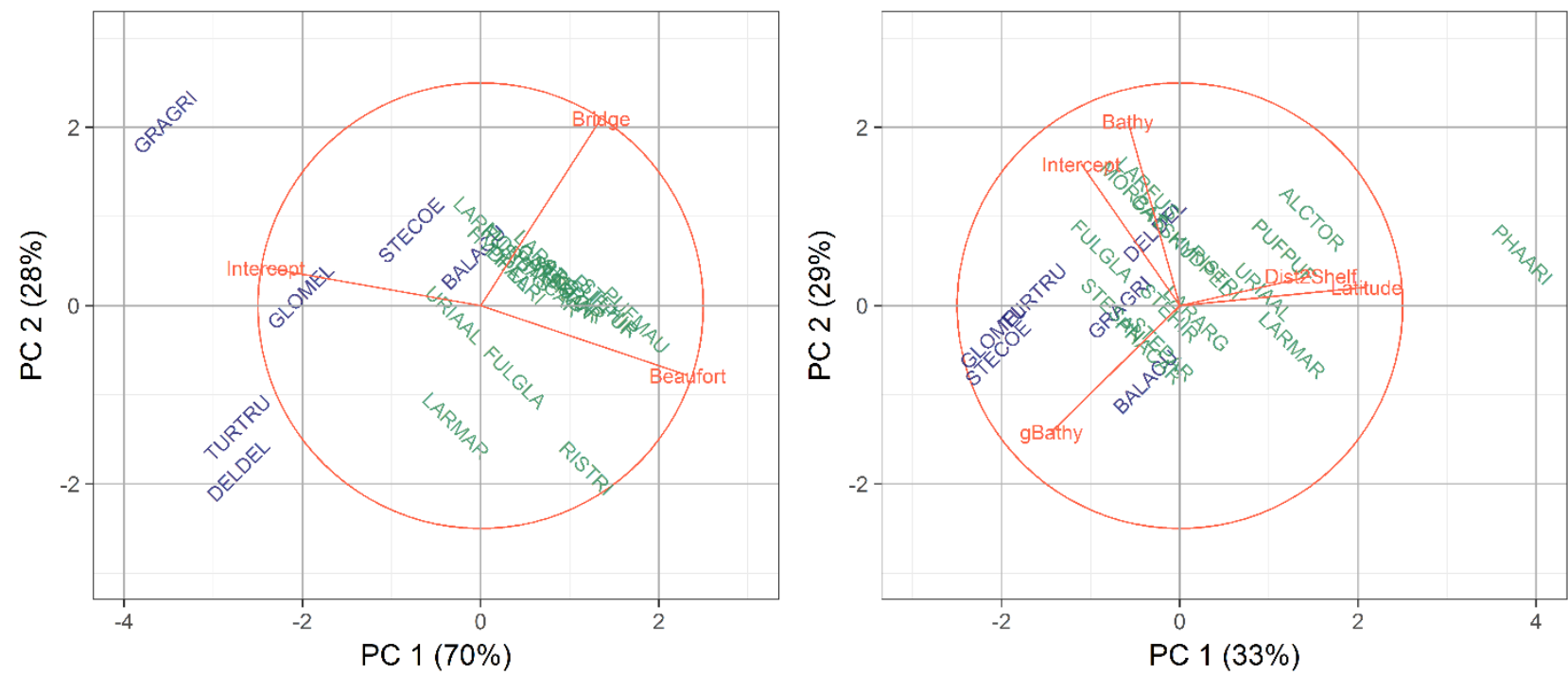

Figure 5: Principal Component Analyses of the regression coefficients estimated with distance sampling: detection (left, panel A) and abundance (right, panel B). Marine mammals are in blue and seabirds in green. 


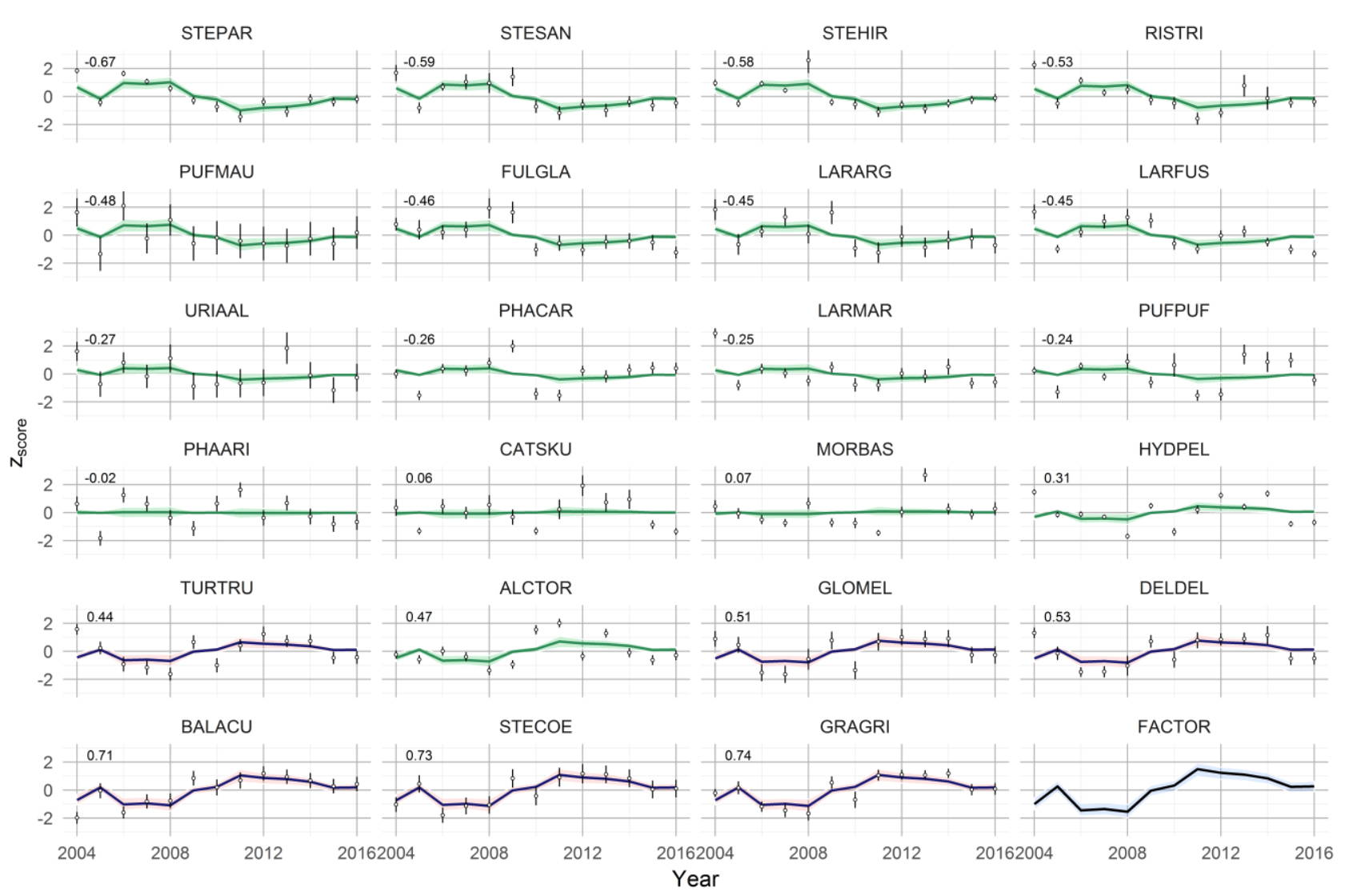

Figure 6: Dynamic Factor Analysis of z-scored time-series (open symbol) of marine megafauna relative abundance in the Bay of Biscay. Species code are given in Table 1. The estimated common factor (black) and its $80 \%$ confidence interval are in the sub-panel in the lower right corner.

Estimated factor loadings are reported in the upper left corner of each subpanel. Marine mammals are in blue and seabirds in green. 
Tables

\begin{tabular}{|c|c|c|c|c|c|c|c|c|c|}
\hline & Family & Species & Scientific name & Code & $\begin{array}{c}\text { Nb. of } \\
\text { Detections }\end{array}$ & $\begin{array}{c}\mathrm{Nb} \text {. of } \\
\text { Individuals }\end{array}$ & $\begin{array}{l}\text { Effective Strip } \\
\text { half-Width }(m)\end{array}$ & $\begin{array}{c}\text { Truncation } \\
\text { distance }(\mathrm{m})\end{array}$ & $\begin{array}{l}\text { Bin } \\
\text { size } \\
(\mathrm{m})\end{array}$ \\
\hline \multirow{17}{*}{ 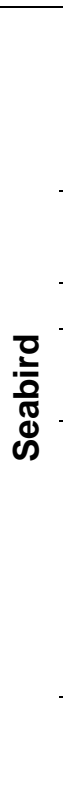 } & \multirow{4}{*}{ Procellaridae } & European storm petrel & Hydrobates pelagicus & HYDPEL & 101 & 238 & 230 & 600 & 100 \\
\hline & & Balearic shearwater & Puffinus mauretanicus & PUFMAU & 113 & 1204 & 250 & 600 & 75 \\
\hline & & Manx shearwater & Puffinus puffinus & PUFPUF & 274 & 710 & 260 & 800 & 100 \\
\hline & & Northern fulmar & Fulmar glacialis & FULGLA & 1375 & 2084 & 250 & 800 & 100 \\
\hline & \multirow{2}{*}{ Phalacrocoracidae } & European shag & Phalacrocorax aristotelis & PHAARI & 36 & 57 & 410 & 800 & 100 \\
\hline & & Great cormorant & Phalacrocorax carbo & PHACAR & 69 & 156 & 280 & 800 & 100 \\
\hline & Sulidae & Northern gannet & Morus bassanus & MORBAS & 7288 & 13646 & 410 & 1200 & 100 \\
\hline & \multirow{2}{*}{ Stercoraridae } & Parasitic skua & Stercorarius parasiticus & STEPAR & 23 & 23 & 200 & 500 & 50 \\
\hline & & Great skua & Catharacta skua & CATSKU & 503 & 622 & 300 & 1000 & 100 \\
\hline & \multirow{6}{*}{ Laridae } & Great black-backed gull & Larus marinus & LARMAR & 96 & 146 & 270 & 700 & 100 \\
\hline & & European herring gull & Larus argentatus & LARARG & 736 & 2347 & 280 & 900 & 100 \\
\hline & & Lesser black-backed gull & Larus fuscus & LARFUS & 2455 & 10507 & 290 & 1000 & 100 \\
\hline & & Black-legged kittiwake & Rissa tridactyla & RISTRI & 207 & 582 & 220 & 700 & 100 \\
\hline & & Common tern & Sterna hirundo & STEHIR & 92 & 244 & 230 & 800 & 100 \\
\hline & & Sandwich tern & Sterna sandvicensis & STESAN & 316 & 636 & 210 & 600 & 100 \\
\hline & \multirow{2}{*}{ Alcidae } & Razorbill & Alca torda & ALCTOR & 30 & 35 & 210 & 500 & 50 \\
\hline & & Common murre & Uria aalge & URIAAL & 929 & 2159 & 190 & 800 & 100 \\
\hline \multirow{6}{*}{ 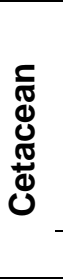 } & \multirow{5}{*}{ Delphinidae } & Risso's dolphin & Grampus griseus & GRAGRI & 18 & 144 & 770 & 1500 & 250 \\
\hline & & Striped dolphin & Stenella coeruleoalba & STECOE & 27 & 733 & 490 & 1500 & 250 \\
\hline & & Long-finned pilot whale & Globicephala melas & GLOMEL & 115 & 1287 & 640 & 2500 & 250 \\
\hline & & Bottlenose dolphin & Tursiops truncatus & TURTRU & 121 & 2388 & 750 & 2000 & 250 \\
\hline & & Common dolphin & Delphinus delphis & DELDEL & 182 & 4757 & 670 & 1500 & 250 \\
\hline & Balaenopteridae & Minke whale & Balaenoptera acutorostrata & BALACU & 24 & 38 & 470 & 1500 & 250 \\
\hline
\end{tabular}

Table 1: Summary statistics of species included in this study. 
$\mathrm{Nb}$. of

\begin{tabular}{clc} 
Factors & \multicolumn{1}{c}{$\boldsymbol{R}$ matrix } & AICc \\
\hline 1 & diagonal with equal variance and zero covariance & 774 \\
1 & nondiagonal with equal variance and equal covariance & $\mathbf{7 2 5}$ \\
2 & diagonal with equal variance and zero covariance & 743 \\
2 & nondiagonal with equal variance and equal covariance & 731 \\
3 & diagonal with equal variance and zero covariance & 744 \\
3 & nondiagonal with equal variance and equal covariance & 739
\end{tabular}

Table 2: Dynamic Factor Analytic model selection with AICc. The best fitting model is highlighted in bold. 